\title{
ELECTROPHYSIOLOGIC STUDIES IN LEPROSY
}

\author{
JOAQUIM P. BRASIL-NETO *
}

SUMMARY - The author reviews the literature on electromyography and nerve conduction velocity studies in leprosy. It is concluded that these studies can be helpful in the early diagnosis of neural involvement, in the elucidation of pathophysiological mechanisms, and in the follow-up of patients under medical and/or surgical treatment.

KEY WORDS: leprosy, electromyography, nerve conduction velocity.

Estudos eletrofisiológicos na hanseniase

RESUMO - O autor faz revisão da literatura acerca dos estudos de eletromiugrafia e de velocidacies de condução nervosa na hanseníase. Conciui que tais estudos podem ser úteis para o diagnóstico precoce do envolvimento neural, para a elucidação de mecanismos fisiopatológicos e para o acompanhamento de pacientes sob tratamento clínico e/ou cirúrgico.

PALAVRAS CHAVE: hanseníase, eletromiografia, velocidade de condução nervosa.

Electromyography (EMG) and nerve conduction velocity (NCV) studies are very important for the study of peripheral neuropathy. In patients with leprosy, therefore, these techniques can also provide information relevant to diagnosis and clinical management. Many studies have addressed this issue, but typically each published paper concentrates on a specific nerve or technique, and the data are therefore scattered in the literature. This paper is an effort to review and summarize such data, and to answer the following questions: 1 . What is the overall electrophysiologic pattern of nerve and muscle involvement in the different clinical forms of leprosy? 2. Can electrophysiologic studies provide any insight into the pathophysiology of nerve involvement in leprosy? 3. Is electrophysiology more sensitive than clinical sensory and motor examination? 4 . Which particular electrophysiologic techniques are most sensitive, showing early changes? 5. How can electrophysiology help clinical decisions in leprosy?

\section{ELECTROPHYSIOLOGIC PATTERN OF PERIPHERAL NERVE AND MUSCLE INVOLVEMENT IN LEPROSY.}

\section{Electromyography:}

Baccareda-Boy et al.4, studying 45 patients (42 lepromatous, 2 tuberculoid and 1 dimorphous) sampled a total of 98 muscles electromyographically; out of them, 38 exhibited various degrees of alterations. These alterations pointed to a peripheral neurogenic type of involvement, and they did not find any evidence of disease of the anterior horn cells of the spinal cord. They did not detect any EMG changes in clinically uninvolved muscles. Other authors have also reported neurogenic EMG traces in the involved muscles of leprosy patients $15,16,18,20,26,27,32$.

*Neurologist and Clinical Neurophysiologist, Hospital for Diseases of the Locomotor System - SARAH, Brasilia, DF, Brazil.

Joaquim P. Brasil Neto, M.D. - 263 Congressional Lane, T-11 - Rockville, MD 20852 - USA. 


\section{Nerve Conduction Velocities:}

II. a. Nerves in the arm - Jopling and Hughes 17 described a case of pure neural tuberculoid leprosy. Their patient had right ulnar and radial nerve thickening, with intrinsic muscle wasting and sensory disturbance in the right hand. NCV in the right ulnar nerve was $41 \mathrm{~m} / \mathrm{sec}$, only slightly below the normal limit (46 $\mathrm{m} / \mathrm{sec})$. However, they realized that this reflected conduction in the fastest fibres, and used a coaxial needle electroae in the hand muscles combined with nerve stimulation. With this technique, they were able to demonstrate markedly reduced NCV $(11-43 \mathrm{~m} / \mathrm{sec})$ in single motor-nerve fibers. Granger et al. 13 also reported their studies of a patient with tuberculoid leprosy; they studied motor NCV (MNCV) in the median, ulnar, tibial and peroneal nerves, and sensory NCV (SNCV) in the median, ulnar and radial nerves, bilaterally. Abnormal MNCV was found in the right median ( $18 \mathrm{~m} / \mathrm{sec}$ ) and ulnar nerve (no response); SNCV could not be determined in the right median, ulnar and radial nerves (no responses). Rosenberg and Lovelace 25 described a case of mononeuritis multiplex in a patient with lepromatous leprosy; their patient showed increased distal latencies in the right median and left ulnar nerves; MNCV was abnormal in the left ulnar nerve $(42.8 \mathrm{~m} / \mathrm{sec})$. Sensory nerve action potentials (SNAPs) were of reduced amplitude in the right and left ulnar and median nerves. Antia et al. 3 studied nerves in the arm (median and ulnar) in 22 patients ( 3 lepromatous, 12 dimorphous, 7 tuberculoid); they found decreased elbow-wrist MNCV in 26 out of $39(66.6 \%)$ ulnar nerves tested. Two patients had increased distal latency in the median nerve, but always associated with decreased elbow-wrist MNCV, suggesting that at least in patients with well-developed neuritis there is no selective compression at the wrist. Antia et al. 2 recorded SNAPs from the index branch of the radial cutaneous nerve (IRC) in both symptomatic (sensory changes in the territory supplied by the IRC) and asymptomatic lepromatous patients; in two thirds of asymptomatic cases, the sensory velocity was in the upper limit of normal or slightly delayed, while the amplitude and duration of the action potential were within the normal range. In the symptomatic cases, conduction was delayed, absent or in the upper limit of normal.

II.b. Nerves in the legs - Swift et al. 31 studied the electrophysiologic pattern of involvement of the peroneal and tibial nerves in lepromatous leprosy in 25 patients. They calculated MNCV for two peroneal nerve segments: from popliteal fossa to the proximal head of the fibula (P1) and from the head of the fibula to the ankle (P2). They recorded latencies from ankle to extensor digitorum brevis muscle (P3) and from the head of the fibula to the tibialis anterior (P4). For the tibial nerve, T1 was the MNCV from popliteal fossa to the medial malleolus, T2 was the latency from ankle to flexor digiti quinti, T3 from ankle to abductor hallucis brevis, and T4 from popliteal crease to the lateral head of the gastrocnemius muscle (Fig. 1). MNCV slowing in the P1 segment was the most common abnormality (13 of 49 legs-26.5\%). P3 and $\mathrm{T} 1$ had the same rate of involvement: 8 of 50 legs $(16 \%)$, and T4 was increased in 7 of $50(14 \%)$. They pointed out that the slowing of tibial MNCV from popliteal fossa to ankle probably was due to pathology in the popliteal fossa or upper calf, since T4 was usually also abnormal and it is the latency to the lateral gastrocnemius nerve, which leaves the tibial nerve in the popliteal fossa. Rosenberg and Lovelace's patient 25 showed increased distal latencies in the left peroneal nerve; MNCV was abnormal in the left peroneal $(26.6 \mathrm{~m} / \mathrm{sec})$ and left posterior tibial nerve (35.9 $\mathrm{m} / \mathrm{sec}$ ). Ndiaye-Niang et al. 22 found involvement of the sural nerve in $54 \%$. of their 37 patients, in contrast with a rate of abnormality of $27 \%$ for the ulnar nerves.

II.c. Facial nerve - Chaco et al.6 studied, electrophysiologically, lagophtal mos in 27 leprosy patients. They concluded that lagophtalmos in leprosy could be caused by weakness of only one part of the orbicularis oculi muscle, and that this might be the result of selective damage to the zygomatic branch of the facial nerve. In general, they found that damage to the ulnar and median nerves preceded damage to the facial nerve. Several other studies detailed the involvement of the facial nerve in leprosy $1,7-9,23,24$.

II.d. Other nerves and muscles - Phrenic nerve conduction was studied and found to be impaired in leprosy 11. Mansour et al.21 reported myopathic changes in EMG in leprosy patients. 


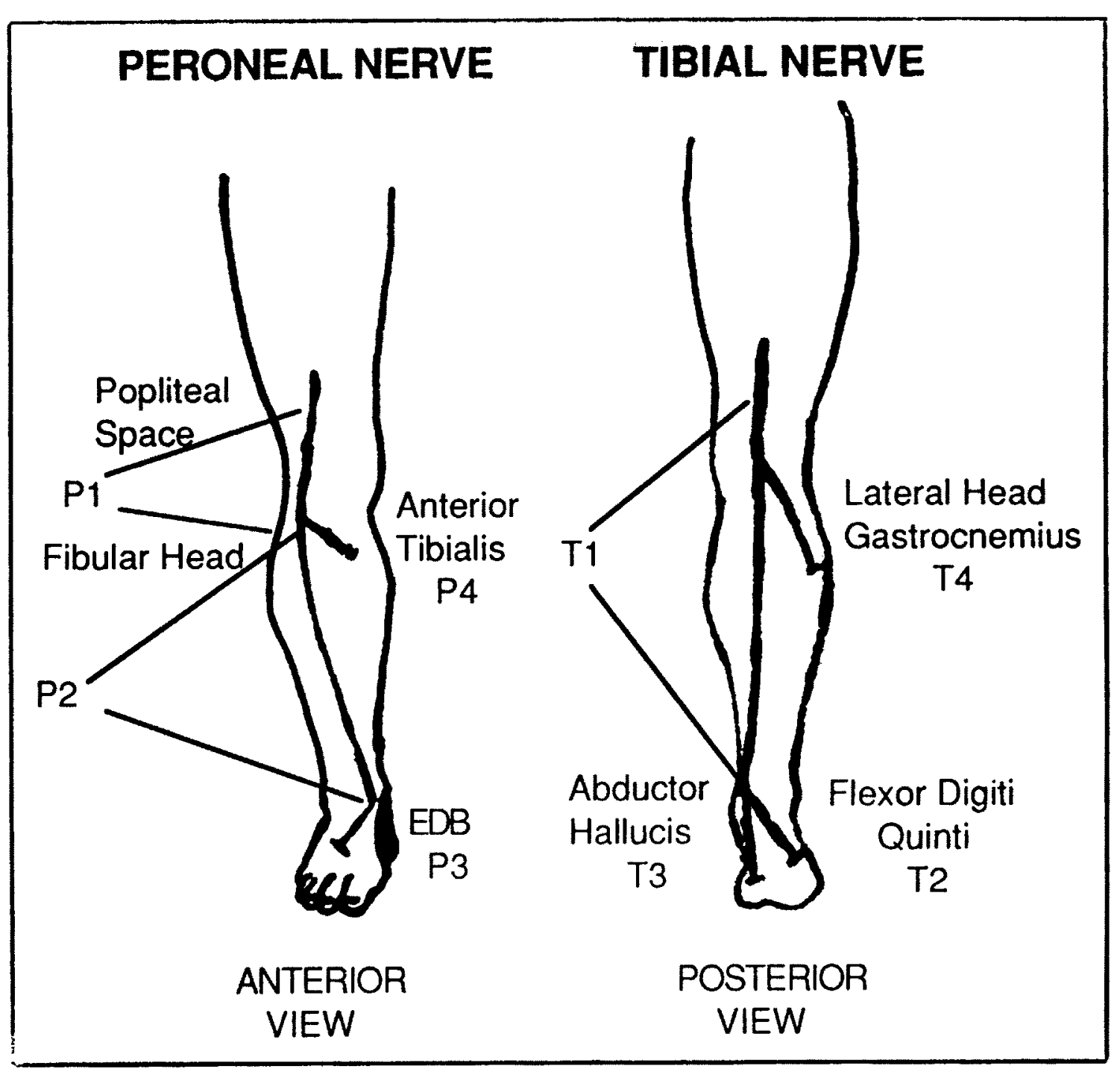

Fig. 1. Diagram showing the different nerve segments in the leg. Adapted from Swift et al.(31) with permission.

\section{ELECTROPHYSIOLOGIC STUDIES AND THE PATHOPHYSIOLOGY OF PERIPHERAL NERVE DISEASE IN LEPROSY.}

Some discrepancies between clinical 19 and EMG/NCV findings in leprosy have helped in elucidating some pathophysiological aspects. Verghese et al.13 were able to detect a good response in clinically paralyzed or very weak muscles with stimulation of the ulnar nerve at the wrist, distally to the presumed site of the lesion. This suggested that the paralysis was due to axonal functional interruption without actual degeneration, and was consistent with involvement of the Schwann cell and/or interstitial tissue. Swift et al.31 also pointed out that the finding of prominent slowing of conduction with no evidence of muscle atrophy in 15 peroneal and 14 tibial nerves in their series was consistent with segmental demyelination of nerve with preservation of axons. The same was suggested by slowing in the proximal segment of the peroneal nerve with normal conduction further distally.

Studying the IRC in leprosy patients without sensory loss in the distribution of this nerve, Antia et al. ${ }^{2}$ found SNAPs of normal amplitude and duration but the sensory conduction velocity was often in the upper limit of normal or slightly delayed. Electron microscopy of the same nerve revealed loss of small myelinated and unmyelinated fibers. Delayed conduction in patients who had sensory loss in the distribution of that nerve was associated with damage to large-sized fibers as well, as shown by electron microscopy.

\section{COMPARISONS BETWEEN ELECTROPHYSIOLOGY AND CLINICAL} TESTING IN LEPROUS PERIPHERAL NEUROPATHY.

Hackett et al.14 studied MNCV in 42 leprosy patients, stimulating at the axilla, midhumerus, $3 \mathrm{~cm}$ above and below the ulnar groove and at the wrist, and 
found patients with normal neurologic evaluation of the ulnar nerve but with abnormally slow conduction at the elbow. Verghese et al.33, however, found normal conduction velocities in 18 of 85 clinically involved ulnar nerves; this probably resulted from the sparing of some of the fast conducting fibers of those 18 nerves; on the other hand, these same authors were able to show MNCV slowing in 14 ulnar nerves without any muscle weakness. Sohi et al.30 also showed a decrease in NCV clinically unaffected nerves.

Rosenberg and Lovelace 25 observed that in their patient with lepromatous leprosy, clinical testing revealed an essentialy symmetrical peripheral distribution of sensory loss, while EMG and NCV studies demonstrated the markedly asymmetric nerve involvement. Antia et al. ${ }^{2}$, even using an improved method of clinical sensory testing, were unable to detect changes in the distribution of the IRC, while both NCV testing and electron microscopy were abnormal.

\section{SENSITIVITY OF DIFFERENT ELECTROPHYSIOLOGIC TESTS IN LEPROSY.}

Antia et al. 3 felt that in early cases concentric needle EMG would be a more sensitive indicator of neural involvement than the study of nerve conduction velocities. On the other hand, a later study by Antia et al.2 showed that abnormalities in the NCV of the IRC may occur very early in the disease, being even more sensitive than quantitative histology and comparable to electron microscopy. Sebille and Gray 26 studied the correlation between needle EMG abnormalities and muscle biopsy, concluding that EMG was better for detecting early denervation. None of these authors, however, made direct comparisons between NCV and needle EMG. Likewise, in their recent series of 80 patients, DeFaria and Silva 10 did not perform needle EMG examinations.

Antia et al. 2 also suggested that, since small myelinated and unmyelinated fibers are involved early in the disease, SNAP recordings with averaging techniques, allowing measurement of late SNAP components corresponding to these small, slow-conducting fibers, would probably be a useful tecnique. A method for studying these late components has recently been reported by Shefner et al.27 in other peripheral neuropathies. We are not aware, however, of any similar study in leprosy patients.

\section{CONTRIBUTIONS OF ELECTROPHYSIOLOGY TO CLINICAL MANAGEMENT IN LEPROSY.}

\section{Surgical management:}

Carayon and Rigal 5 outlined several general guidelines concerning the role of EMG and NCV stuaies in surgical indications in leprosy. These may be summarized as follows:

I.a. Recet neuritis - Characterized by algo-parethic phenomena, often brutal in onset, it can be either a mononeuritis or a multineuritis. Negative NCV and EMG results do not contraindicate surgery after medical treatment. Surgery is especially indicated in the early stages of neuritis, to improve or halt the progression of the sensory-motor deficit. There is often improvement in EMG/ NCV after surgery. When there is a remission induced by thalidomide, there is often a rebound; in these cases, if NCV drops and EMG worsens, it is a sign of failure of medical treatment and there is surgical indication. When the neuritis is subclinical, and NCV and EMG are stable, medical treatment alone should be pursued; if EMG/NCV results deteriorate in spite of medical treatment, surgery should be considered.

I.b. Long-standing neuritis - If there are clinically complete sensory-motor deficits and EMG/NCV results are very abnormal, surgery is contraindicated; if EMG shows some intact motor units and signs of regeneration, surgery can be indicated. Here Carayon and Rigal 5 provide a "rule of thumb": they have found surgery worthwile only when NCV is more than $25-30 \mathrm{~m} / \mathrm{s}$. A special case is when there is progressive hand mutilation with preservation of motor function; in such instances, it is difficult to propose surgical decompression of the 
median nerve at the wrist. However, if NCV and EMG are abnormal, showing subclinical motor involvement, surgery can be justified.

\section{Monitoring of medical treatment:}

Granger et al.12 found, in a patient with tuberculoid leprosy tested serially for NCV, that improvement of these velocities correlated well with periods of apparent remission of the disease, although there were no changes in clinically assessed sensory functions or reflex activity.

Rosenberg and Lovelace 25 studied a patient with lepromatous leprosy with NCV before and after dapsone therapy. There was improvement in 4 out of 12 nerves tested after 5 months of therapy. DeFaria and silva 10 also detected improvement in NCV in some patients after 4 months of dapsone therapy.

Sheskin et al.29 studied 6 patients with lepromatous leprosy who had 17 leprosy reactions treated with thalidomide, 6 reactions treated with prednisone, 3 with analgesics and 2 with placebo. They found that both thalidomide and prednisone had a suppressive effect upon the neurologic manifestations, including the impairment of MNCV, and concluded that MNCV can be used to monitor drug efficacy in leprosy reactions.

\section{CONCLUSIONS}

This review of the literature allows the following conclusions:

1. There is extensive involvement of peripheral nerves in leprosy, but sta. tistically some specific nerves and sites predominate. The view that more superficial and therefore cooler nerve paths are preferentially involved in leprosy is challenged by a recent report of involvement of the phrenic nerve.

2. EMG and NCV studies give support to the notion that segmental de myelination with axonal preservation is the initial form of nerve involvement in leprosy. However, small unmyelinated and myelinated fibers are involved early in the disease.

3. Both EMG and NCV are more sensitive than clinical examination and EMG may be even better than muscle biopsy in the detection of muscle denervation in leprosy.

4. There is not a consensus as to whether EMG or NCV is the most sensitive technique in the detection of early neural involvement in leprosy.

5. Serial EMG and NCV studies are useful for assessing the effects of medical therapy and for surgical indications in neural leprosy.

\section{REFERENCES}

1. Antia NH, Divekar SC, Dastur DK. The facial nerve in leprosy: I. Clinical and operative aspects. Internat $\mathrm{J}$ Leprosy 1966, 34:103-117.

2. Antia NH, Mehta L, Shetty V, Irani PF. Clinical, electrophysiological, quantitative, histologic and ultrastructural studies of the index branch of the radial cutaneous nerve in leprosy: I. Preliminary report. Internat $J$ Leprosy 1975, 43:106-113.

3. Antia NH, Pandya SS, Dastur DK. Nerves in the arm in leprosy. I. Clinical, electrodiagnostic and operative aspects. Internat $J$ Leprosy. Mycobact Dis 1970, 38:12-29.

4. Baccareda-Boy A, Mastropaoli C, Pastorino P, Sacco G, Farris G. Electromyographic findings in leprosy. Internat $\mathrm{J}$ Leprosy 1963, 31:531-532.

5. Carayon A, Rigal J. Value of electrophysiological investigation for therapeutic indications in leprous neuritis. Med Trop (Mars) 1972, 32:9-21.

6. Chaco J, Magora A, Zauberman H, Landau Y. An electromyographic study of lagophthalmos in leprosy. Internat $J$ Leprosy Mycobact Dis 1968 36:288-295.

7. Dastur DK. Leprosy (an infectious and immunological disorder of the nervous system). In Vinken PJ, Bruyn GW (eds): Handbook of Clinical Neurology. Amsterdam: Elsevier/ North-Holland, 1978, Vol 33, p 421-468.

8. Dastur DK, Antia NH, Divekar SC. The flacial nerve in leprosy: 2. Pathology, pathogenesis, electromyography and clinical correlations. Internat $J$ Leprosy Mycobact Dis 1966 , $34: 118-138$. 
9. Dastur DK, Pandya SS, Antila NH. Nerves in the arm in leprosy: 2. Pathology, pathogenesis and clinical correlations. Internat $J$ Leprosy 1970, 38:30-48.

10. DeFaria CR, Silva IM. Electromyographic diagnosis of leprosy. Arq Neuropsiquiatr 1990, 48:403-413.

11. Dhand UK, Kumar B, Dhand R, Chopra JS, Kaur S. Phrenic nerve conduction in leprosy. Internat $\mathrm{J}$ Leprosy Mycobact Dis 1988, 56:389-393.

12. Donde SV, Shah A, Antia NH. Nerve conduction in leprosy: in vivo and in vitro study. Lepr India 1983, 55:12-21.

13. Granger CV. Nerve conduction and correlative clinical studies in a patient with tuberculoid leprosy. Am J Phys Med 1966, 45:244-250.

14. Hackett ER, Shipley DE, Livengood $R$. Motor nerve conduction vellocity studies of the ulnar nerve in patients with leprosy. Internat $J$ Leprosy Mycobact Dis 1968, 36:282-287.

15. Haridasan G, Sanghvi SH, Joshi VM, Pandya SS, Desai AD. Quantitative electromyography using automatic analysis: diagnostic utility of turns per unit amplitude. J Neurol Sci 1980, $48: 353-365$

16. Herskovits E, Chamoles N. Neuro-leprosy: value of electromyography. Arq Neuropsiquiatr $1971,29: 337-340$

17. Jopling WH, Morgan-Hughes JA. Pure neural tuberculoid leprosy. Br Med J 1965, 2:799-800.

18. Kandhari KC, Sehgal VN. Electromyographic studies in leprosy and dermatomyositis. Dermatol Internat 1965, 4:96-101.

19. Lewis S. Reproducibility of sensory testing and voluntary muscle testing in evaluating the treatment of acute' neuritis in leprosy patients. Lepr Rev 1983, 54:23-30.

20. Magora A, Sagher F, Chaco J, Adler W. An electrodiagnostic study of the lcwer motor unit in leprosy. Internat $J$ Lepr 1965, 33:829-864.

21. Mansour SE, Mehasen A, el-Ariny AF. Muscular changes in lepromatous ieprosy. Trans $R$ Soc 'írop Med Hyg 1970, 64:918-920.

22. Ndiaye-Niang $M$, Diagne $M$, Ndiaye IP, Boucher $P$, Millan J. The valiue of electromyographic studies in leprosy. Acta Leprol 1986, 4:51-58.

23. Ranney DA. The prevalence and consequences of misreinnervation in facial neuritis. Internat $J$ Leprosy Mycobact Dis 1974, 42:316-322

24. Ranney DA, Furness MA, Santhanakrishnan CK. Misreinnervation in leprous neuritis affecting the tacial nerve. Lepr Rev 1973, 43:151-158.

25. Rosenberg RN, Lovelace RE. Mononeuritis multiplex in lepromatous leprosy. Arch Neurol 1968, $19: 310-314$.

26. Sebille A, Gray F. Exectromyographic recording and muscle biopsy in lepromatous leprosy. J Neurol Sci 1979, 40:3-10.

27. Sena PG. Electromographic and neurological aspects of leprosy: study of 100 cases. Arq Neuropsiquiatr 1976, 34:1-17.

28. Shefner JM, Buchtal F, Krarup C. Slowly conducting myelinated fibers in peripheral neuropathy. Muscle Nerve 1991, 14:534-542.

29. Sheskin 5, Magora A, Sagher F. Motor conduction velocity studies in patients with leprosy reaction treated with thalidomide and other drugs. Internat $J$ Leprosy 1969, 37:359364.

30. Sohi AS, Kandhari KC, Singh N. Motor nerve conduction studies in leprosy. Internat J Dermatol 1971, 10:151-155.

31. Swift TR, Hackett ER, Shipiey DE, Miner KM. The peroneal and tibial nerves in lepromatous leprosy: clinical and electrophysiologic observations. Internat $J$ Leprosy Mycobact Dis 1973, $41: 25-34$

32. Thiers H, Bouillat G, Bourrat C, Descos L. Electromographic study of two cases of neural leprosy observed in the Dermatology Clinic. $J$ Med Lyon 1966, 47:1811-1813.

33. Verghese M, Ittimani KV, Satyanarayan KR, Mathai R, Bhakthaviziam C. A study of the conduction velocity of the motor fibers of ulnar and median nerves in leprosy. Internat J Leprosy Mycobact Dis 1970, 38:271-277. 